\title{
Serum $14-3-3 \eta$ level is associated with severity and clinical outcomes of rheumatoid arthritis, and its pretreatment level is predictive of DAS28 remission with tocilizumab
}

\author{
Shintaro Hirata ${ }^{1}$, Anthony Marotta ${ }^{2}$, Yuan Gui ${ }^{2}$, Kentaro Hanami ${ }^{1}$ and Yoshiya Tanaka ${ }^{1 *}$
}

\begin{abstract}
Introduction: Treat-to-target strategies to achieve low disease activity or clinical remission are key in the treatment of rheumatoid arthritis (RA). 14-3-3n is a joint-derived biomarker that is expressed at significantly higher levels in patients with RA than in healthy subjects, other autoimmune diseases, or viral and bacterial arthritides. In this study, we sought to investigate the utility of pretreatment levels of $14-3-3 \eta$ and serial measurement of $14-3-3 n$ to inform therapeutic outcomes.
\end{abstract}

Methods: Serum 14-3-3n levels were measured in 149 Japanese patients with RA before the initiation of therapy and at 1-year follow-up. Patients were treated with either methotrexate (MTX), adalimumab (ADA), tocilizumab (TCZ), or tofacitinib (TOF). 14-3-3n positivity was defined as $\geq 0.19 \mathrm{ng} / \mathrm{ml}$ and at two times and four times this cutoff. In contingency analysis, we determined the association of 14-3-3n with disease severity. Wilcoxon matched-pairs test was used to evaluate the significance of pre- to post-treatment changes. Mann-Whitney $U$ test was performed for differences between treatment response groups. Fisher's exact test was used to assess associations of 14-3-3n with a good response defined by European League Against Rheumatism criteria as well as remission defined by the Disease activity Score in 28 joints with erythrocyte sedimentation rate (DAS28-ESR) and the Clinical Disease Activity Index score.

Results: 14-3-3n-positive patients had more severe disease before the initiation of treatment. When combined with C-reactive protein (CRP), 14-3-3n positivity added significantly and incrementally to the identification of patients with high disease activity. 14-3-3n levels were significantly decreased at 1 year and were modifiable across all classes of therapeutics. Patients who reverted to negative 14-3-3n levels had better clinical response than patients who remained positive at 1 year or became positive. Pretreatment 14-3-3n levels informed 1-year DAS28-ESR remission in the TCZ-treated group, in contrast to the ADA, MTX, or TOF groups, while no differences in pretreatment 14-3-3n expression based on clinical response.

Conclusions: $14-3-3 n$ is a modifiable marker in identifying patients with RA in a high disease state. Patients who achieve a negative 14-3-3n status following 1-year of treatment do better clinically with pretreatment 14-3-3n informing response to TCZ.

\footnotetext{
* Correspondence: tanaka@med.uoeh-u.ac.jp

${ }^{1}$ First Department of Internal Medicine, School of Medicine, University of Occupational and Environmental Health, 1-1 Iseigaoka, Yahatanishi, Kitakyushu 807-8555, Japan

Full list of author information is available at the end of the article
} 


\section{Introduction}

Because rheumatoid arthritis (RA) is a multifactorial disease with a heterogeneous presentation and disease course, identifying patients with aggressive early RA for prompt and appropriate treatment is critical to minimize irreversible joint destruction and disability [1]. If there is intolerance or an inadequate response to initial therapy with methotrexate (MTX) or another synthetic diseasemodifying antirheumatic drug (sDMARD), treatment should be intensified to achieve remission or low disease activity. Numerous biologic therapies targeting different inflammatory pathways have been developed for the treatment of RA, including those that target tumor necrosis factor (infliximab, etanercept, adalimumab [ADA], certolizumab, and golimumab), T-cell costimulation (abatacept), B-cell depletion (rituximab), and the interleukin 6 receptor (tocilizumab [TCZ]). Recently, small-molecule kinase inhibitors have been developed as therapeutics for RA, including the Janus kinase inhibitor tofacitinib (TOF).

Importantly, even with early identification of RA and prompt initiation of treatment, up to $70 \%$ of patients do not attain a satisfactory clinical response with therapy switches within and between drug classes. This heterogeneous response to therapy provides strong evidence that RA is likely caused by any one or a number of different biochemical pathways acting alone and/or in concert, resulting in the manifestation of common symptomology and disease presentation. Notably, the pathologic factors in early and late RA differ with respect to cytokine profiles $[2,3]$. These differences, together with heterogeneous treatment response, indicate that there are fundamental differences in the pathological processes based on the stage of disease. This situation highlights the need for biomarkers that can assist with personalizing treatment strategies. Coupled with this information are the results of phase III clinical trials demonstrating that the pathways that drive the inflammatory process might be distinct from those that ultimately lead to erosive disease [4-8].

14-3-3 proteins are an evolutionarily conserved family of molecular chaperones that play a critical role in the regulation of intracellular functions, including proliferation, differentiation, and metabolism, among other functions. The 14-3-3 family consists of seven isoforms: alpha/ beta $(\alpha / \beta)$, epsilon $(\varepsilon)$, gamma $(\gamma)$, eta $(\eta)$, tau $(\tau)$, zeta $(\zeta)$, and sigma $(\sigma)$. In 2007, Kilani et al. reported that, on the

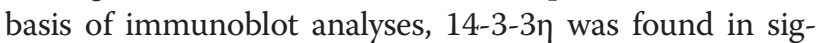
nificantly higher amounts in the serum and synovial fluid of patients with inflammatory arthritis compared with healthy subjects [9]. In 2014, Maksymowych et al. re-

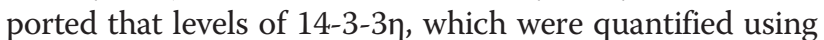
a 14-3-3 $\eta$ enzyme-linked immunosorbent assay (ELISA), were detectable at significantly higher levels in patients with early and established RA than in healthy subjects and patients with various autoimmune disorders and other arthritides [10]. They also found, through receiver operating characteristic curve analysis, that levels $\geq 0.19 \mathrm{ng} / \mathrm{ml}$ were highly discriminative for RA, with increasing 14-3$3 \eta$ positivity cutoffs providing greater discriminatory power for the identification of RA. They also reported that the 14-3-3 $\eta$ levels did not correlate with acute-phase reactants such as C-reactive protein (CRP) and that common factors present in the serum, including rheumatoid factor (RF), did not interfere with the quantification of 14-3-3n [10]. Other studies have further confirmed the differential

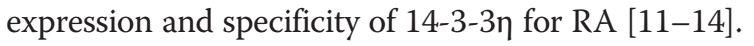

In the present study, we evaluated $14-3-3 \eta$ serum expression levels in a cohort of Japanese patients with established RA before the initiation of therapy and following 1 year of treatment with commonly used therapies, each with a differing mechanism of action, including MTX, ADA, TCZ, and TOF, in daily clinical practice. The relationship between disease severity,

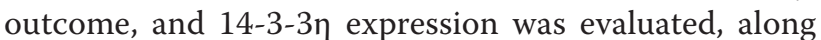
with the utility of $14-3-3 \eta$ as a marker in informing therapy response.

\section{Methods}

\section{Patient cohort}

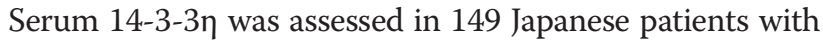
established RA, classified according to the American College of Rheumatology 1987 criteria [15], before the initiation of therapy with MTX, ADA, TCZ, or TOF and following 1 year of treatment in daily clinical practice. The vast majority of patients in this study were women (86 \%), and the cohort had a mean (standard deviation) age of 57 (15) years and a median (interquartile range [IQR]) disease duration of 51 (9-150) weeks. A total of 23 patients received MTX, 49 received ADA, 50 received TCZ, and 27 received TOF. Clinical examinations by a certified rheumatologist were completed for all patients before initiation of therapy and after 1 year of treatment. Assessments included Disease Activity Score in 28 joints with erythrocyte sedimentation rate (DAS28-ESR), Clinical Disease Activity Index (CDAI), Simple Disease Activity Index (SDAI), 28-joint tender joint count (TJC28), 28-joint swollen joint count (SJC28), Sharp/van der Heijde score (SHS), joint space narrowing (JSN), and erosion score. Serological assessments included erythrocyte sedimentation rate (ESR), CRP, RF, and anticitrullinated protein antibodies (ACPA). The study was performed in accordance with the Declaration of Helsinki. Written informed consent was obtained from all study participants, and ethical approval was received from the University of Occupational and Environmental Health, Japan.

\section{Serum 14-3-3n measurements}

Serum 14-3-3 $\eta$ levels were measured using a quantitative 14-3-3 $\eta$ ELISA kit (Augurex Life Sciences Corporation, 
Vancouver, BC, Canada). A 14-3-3ך cutoff of $\geq 0.19 \mathrm{ng} / \mathrm{ml}-$ the positivity cutoff established by Maksymowych et al. [10] - was used to define 14-3-3 $\eta$ positivity. Two additional 14-3-3 $\eta$ positivity cutoffs also described by Maksymowych et al. [10] were used: one at twice the positivity cutoff $(\geq 0.40 \mathrm{ng} / \mathrm{ml})$ and the other at four times the positivity cutoff $(\geq 0.80 \mathrm{ng} / \mathrm{ml})$.

\section{Statistical analyses}

The Mann-Whitney $U$ test was used to assess clinical and serological differences between treatment groups at initiation and after 1 year of therapy. The relationship of $14-3-3 \eta$ to clinical measures was assessed using Spearman's rank correlation coefficient. Contingency analysis provided the strength of association of $14-3-3 \eta$ status with DAS28-ESR, CDAI, and SDAI categorization (i.e., remission or low, moderate, or high disease state). To assess the complementarity between 14-3-3 $\eta$ and CRP in identifying patients in a CDAI-defined high disease state, CRP positivity was defined as $\geq 10 \mathrm{mg} / \mathrm{L}$. Patients were categorized as being either negative for both markers, positive for any one of the two markers, or positive for both markers. The Wilcoxon matched-pairs signed-rank test was used to evaluate the significance of pre- to posttreatment changes in 14-3-3ๆ levels within therapy groups. An unpaired $t$ test assuming equal variances was used to compare differences between groups with fewer than 10 patients. Fisher's exact test was employed to determine the association between positivity of $14-3-3 \eta$ and a good response as defined by European League Against Rheumatism (EULAR) criteria [16] or remission as defined by DAS28-ESR. DAS28-ESR and CDAI remission were defined as scores $<2.6$ and $\leq 2.8$, respectively. All statistical analyses were completed with Prism 6 (GraphPad Software, La Jolla, CA, USA) or JMP 11 (SAS Institute, Cary, NC, USA) software. A $p$ value $<0.05$ denoted statistical significance.

\section{Results}

Positivity of 14-3-3n informs a worse disease state

Before the initiation of therapy, 110 patients (74\%) were

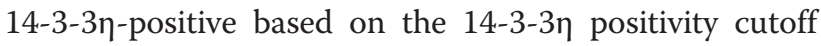

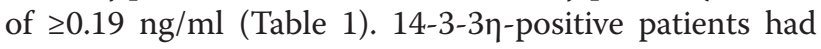
significantly higher median (IQR) DAS28-ESR, CDAI, SDAI, TJC28, and SJC28 scores at initiation than pa-

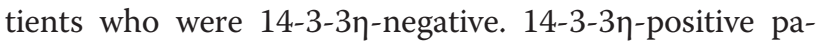
tients also had significantly higher ESR, ACPA, and RF levels.

Spearman's correlation analysis revealed that titers of 14-3-3 $\eta$ at therapy initiation correlated modestly with DAS28-ESR, CDAI, SDAI, JSN, TJC28, SJC28, CRP, and ESR values (Table 2). Contingency analysis revealed a strong and significant association at initiation between patients in higher 14-3-3 $\eta$ cutoff categories with moderate and/or high disease severity across the three different indices: DAS28-ESR, CDAI, and SDAI (Table 3). Because 14-3-3 $\eta$ had a modest correlation with CRP, the complementarity of these two markers in identifying patients with a CDAI-defined high disease status was assessed. As depicted in Table 3, using the $\geq 0.80 \mathrm{ng} / \mathrm{ml}$ cutpoint

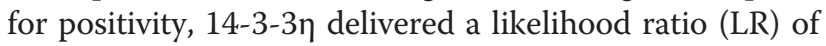
14.0. Positivity for CRP based on $\geq 10 \mathrm{mg} / \mathrm{L}$ delivered a significant and strong LR of $20.5(p<0.0001)$. As illustrated in Fig. 1a and described herein, positivity for both $14-3-3 \eta$ and CRP identified a significantly higher proportion of patients who are in a CDAI-defined high disease state than those who are positive for any one of the two markers or negative for both. The LR for CRP increased from 20.5 to $37.69 p<0.0001)$ when both markers were combined. This complementarity with CRP was also observed at the $0.19 \mathrm{ng} / \mathrm{ml}$ positivity cutoff for 14-3-3 $\eta$, with the combined LR being 24.3 ( $p<$ $0.0001)$.

\section{Levels of $14-3-3 \eta$ are modifiable overtime}

After 1 year of treatment, 97 patients (65\%) were 14-3$3 \eta$-positive. The data in Table 4 and Fig. $1 \mathrm{~b}$ demonstrate that pretreatment $14-3-3 \eta$ serum levels were significantly higher than 1-year levels across the whole group $(p<0.0001)$. As illustrated in Fig. 1c, the levels of 14-3$3 \eta$ either increased, decreased, or stayed the same over time. Of the 110 patients who were positive for 14-3-3n before the initiation of treatment, 18 reverted or became negative (BN) based on the $\geq 0.19 \mathrm{ng} / \mathrm{ml}$ positivity cutoff, whereas 92 remained positive (RP). Of the 39 patients who were negative at treatment initiation, 5 converted at 1 year or became positive (BP) based on the $0.19 \mathrm{ng} / \mathrm{ml}$ positivity cutoff, whereas 34 remained negative (RN).

The Kruskal-Wallis test revealed a significant difference in DAS28-ESR at 1 year between the four $14-3-3 \eta$ modifiability groups (stayed negative, $\mathrm{BN}$, stayed positive [SP], BP) $(p=0.014)$. DAS28-ESR levels were not significantly different among the four different groups before the initiation of treatment. By post hoc Dunn's testing, a significant difference $(p \leq 0.05)$ in median DAS28-ESR levels was demonstrated between $\mathrm{BN}$ patients (2.01; 1.60-2.80) and SP patients (5.27; 4.57-7.34) (Fig. 1d). The Mann-Whitney $U$ test further highlighted this difference $(p=0.004)$. To assess whether a difference in 1year DAS28-ESR existed between the BP group versus the $\mathrm{BN}$ group, an unpaired $t$ test assuming equal variances revealed that mean DAS28-ESR 1-year levels were significantly lower in the $18 \mathrm{BN}$ patients than in the 5 $\mathrm{BP}$ patients $(2.09 \pm 0.18$ vs $3.09 \pm 0.52 ; p=0.033)$.

\section{Relationship of 14-3-3n to therapy}

As shown in Table 4, the levels of $14-3-3 \eta$ before the initiation of therapy and the posttreatment levels at 1 year were significantly different across all four classes 
Table 1 Pretreatment patient characteristics

\begin{tabular}{|c|c|c|c|c|}
\hline Variable & Entire cohort & 14-3-3n-negative & 14-3-3n-positive & $p$ Value \\
\hline Number of patients & 149 & 39 & 110 & \\
\hline \multicolumn{5}{|l|}{ Categorical variables } \\
\hline Sex (\% female) & $128(86 \%)$ & $34(87 \%)$ & $94(85 \%)$ & 0.7937 \\
\hline RF status (\% positive) & $126(85 \%)$ & $21(54 \%)$ & 105(95 \%) & $<0.0001$ \\
\hline ACPA status (\% positive) & $97(65 \%)$ & $20(67 \%)^{a}$ & $78(98 \%)^{b}$ & $<0.0001$ \\
\hline 14-3-3n status (\% positive) & $110(74 \%)$ & $0(0 \%)$ & $110(100 \%)$ & $<0.0001$ \\
\hline Concomitant use of MTX (\%) & 117 (79 \%) & $34(87 \%)$ & $83(76 \%)$ & 0.1733 \\
\hline \multicolumn{5}{|l|}{ Continuous variables } \\
\hline Age $(y r)^{c}$ & $57.3(14.7)$ & $54.6(16.1)$ & $58.2(14.1)$ & 0.1924 \\
\hline RA duration (mo) & $51(9-150)$ & $34(9-132)$ & $55(11-159)$ & 0.3791 \\
\hline MTX dose (mg/wk) & $8.0(5.0-10.0)$ & $8.0(6.0-10.0)$ & $8.0(1.5-10.0)$ & 0.456 \\
\hline DAS28-ESR & $5.35(4.40-6.45)$ & $4.77(4.10-5.86)$ & $5.62(4.64-6.57)$ & 0.0101 \\
\hline$H A Q^{d}$ & $1.07(0.60-1.88)$ & $1.00(0.47-1.88)$ & $1.13(0.63-1.85)$ & 0.7328 \\
\hline CDAl & $22.2(14.0-33.5)$ & $16.0(11.5-27.0)$ & $24.7(16.2-36.3)$ & 0.015 \\
\hline SDAl & $24.3(14.3-37.4)$ & $18.8(11.7-32.7)$ & $26.8(16.7-38.6)$ & 0.0238 \\
\hline TJC28 & $7.0(4.0-13.5)$ & $5.0(2.0-12.0)$ & $7.0(4.0-14.0)$ & 0.0327 \\
\hline SJC28 & $6.0(2.0-9.0)$ & $4.0(2.0-9.0)$ & $6.5(2.8-10.0)$ & 0.0466 \\
\hline SHS & $26.5(4.5-90.8)$ & $14.0(3.0-88.5)$ & 31.3 (6.9-99.9) & 0.1185 \\
\hline JSN score ${ }^{e}$ & $18.0(3.0-45.5)$ & $9.0(1.5-42.5)$ & $19.8(4.1-47.4)^{f}$ & 0.11 \\
\hline Erosion score ${ }^{e}$ & $10.5(2.0-45.5)$ & $5.0(2.0-40.5)$ & $12.8(2.5-53.0)^{f}$ & 0.108 \\
\hline ESR & $44.0(21.5-72.5)$ & $35.0(17.0-58.0)$ & $47.5(22.8-80.0)$ & 0.0482 \\
\hline CRP (mg/dl) & $0.83(0.23-3.13)$ & $0.69(0.20-2.70)$ & $0.99(0.26-3.44)$ & 0.3769 \\
\hline RF & $60.4(27.4-171.8)$ & $15.5(5.8-43.2)$ & $84.5(41.9-242.1)$ & $<0.0001$ \\
\hline ACPA & $100.0(27.4-100)$ & $16.9(1.9-100)^{\mathrm{a}}$ & $100.0(52.0-100)^{b}$ & 0.0002 \\
\hline $14-3-3 n(\mathrm{ng} / \mathrm{ml})$ & $0.70(0.17-5.96)$ & $0.10(0.04-0.13)$ & $1.70(0.49-11.0)$ & $<0.0001$ \\
\hline
\end{tabular}

Abbreviations: ACPA anticyclic citrullinated antibodies, CDAI Clinical Disease Activity Index, CRP C-reactive protein, DAS28-ESR Disease Activity Score in 28 joints with erythrocyte sedimentation rate, ESR erythrocyte sedimentation rate, HAQ Health Assessment Questionnaire, JSN joint space narrowing, MTX methotrexate, RF rheumatoid factor, RA rheumatoid arthritis, SDAI Simple Disease Activity Index, SHS Sharp/van der Heijde score, SJC28 28-joint swollen joint count, TJC28 28-joint tender joint count

All $p$ values were generated based on Mann-Whitney analysis, with the exception of age, which was generated using paired $t$ tests.

${ }^{\mathrm{a}}$ Data were available for 30 patients

${ }^{\mathrm{b}} \mathrm{ACPA}$ values were available for 80 patients

${ }^{\mathrm{C}} \mathrm{Age}$ is presented as the mean (standard deviation). All other variables are presented as the median (interquartile range).

${ }^{\mathrm{d}} \mathrm{HAQ}$ scores were available for 146 patients

eJSN and erosion scores were available for 147 patients

fJSN and erosion scores were available for 108 patients

of therapy. Response rates across the whole cohort based on DAS28-ESR-defined remission and a EULAR-defined good response were $55 \%$ and $71 \%$, respectively. When we examined the differential expression of $14-3-3 \eta$ by

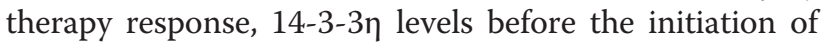
therapy emerged as significantly lower in the TCZ treated group that achieved DAS28-ESR remission. This finding was in contrast to those in the ADA, MTX, and TOF treated groups (Table 5), where no difference was seen in the levels of the 14-3-3 $\eta$ before the initiation of treatment. Interestingly, no significant differences in pretreatment CRP levels were observed across the whole cohort and within the different therapy groups. Similar to $14-3-3 \eta$, CRP levels at 1 year were significantly lower in the TCZ group that achieved a DAS28 ESR remission. For a EULAR-defined good response, whereas 14-3-37 baseline levels in these groups appeared different, the nonresponder subgroup was too small to return a significant difference.

Fisher's exact test revealed that pretreatment 14-3-3n at all positivity cutpoints was associated with the achievement of DAS28-ESR remission in TCZ-treated patients with pretreatment levels of $\leq 0.40 \mathrm{ng} / \mathrm{ml}$, delivering the strongest LR of $15.67(p=0.0001)$. As DAS28ESR levels at initiation were significantly lower in DAS28-ESR remitters in the TCZ group (Table 5), controlling for DAS28-ESR in a multivariable regression model demonstrated that a $14-3-3 \eta$ level $\leq 0.40 \mathrm{ng} / \mathrm{ml}$ 
Table 2 Spearman's correlation coefficients of pretreatment clinical variables with 14-3-3n

\begin{tabular}{|c|c|c|c|c|c|c|c|c|c|c|c|c|}
\hline Variables & DAS28-ESR & SDAI & CDAl & HAQ & SHS & JSN score & Erosion score & TJC28 & SJC28 & $14-3-3 n$ & CRP & ESR \\
\hline \multicolumn{13}{|l|}{ DAS28-ESR } \\
\hline SDAI & $0.91^{\mathrm{a}}$ & & & & & & & & & & & \\
\hline CDAl & $0.89^{a}$ & $0.99^{\mathrm{a}}$ & & & & & & & & & & \\
\hline HAQ & $0.59^{\mathrm{a}}$ & $0.54^{\mathrm{a}}$ & $0.53^{\mathrm{a}}$ & & & & & & & & & \\
\hline SHS & $0.34^{\mathrm{a}}$ & $0.28^{b}$ & $0.27^{\mathrm{b}}$ & $0.43^{\mathrm{a}}$ & & & & & & & & \\
\hline JSN score & $0.33^{\mathrm{a}}$ & $0.28^{b}$ & $0.27^{b}$ & $0.41^{\mathrm{a}}$ & $0.98^{\mathrm{a}}$ & & & & & & & \\
\hline Erosion score & $0.32^{\mathrm{a}}$ & $0.24^{b}$ & $0.23^{b}$ & $0.43^{\mathrm{a}}$ & $0.97^{\mathrm{a}}$ & $0.91^{\mathrm{a}}$ & & & & & & \\
\hline TJC28 & $0.80^{\mathrm{a}}$ & $0.86^{\mathrm{a}}$ & $0.89^{\mathrm{a}}$ & $0.45^{\mathrm{a}}$ & $0.19^{c}$ & $0.19^{c}$ & 0.16 & & & & & \\
\hline SJC28 & $0.73^{\mathrm{a}}$ & $0.84^{\mathrm{a}}$ & $0.84^{\mathrm{a}}$ & $0.33^{\mathrm{a}}$ & $0.35^{\mathrm{a}}$ & $0.33^{\mathrm{a}}$ & $0.28^{b}$ & $0.69^{\mathrm{a}}$ & & & & \\
\hline $14-3-3 n$ & $0.29^{\mathrm{a}}$ & $0.24^{b}$ & $0.25^{d}$ & 0.05 & 0.16 & $0.18^{c}$ & 0.16 & $0.21^{c}$ & $0.26^{\mathrm{b}}$ & & & \\
\hline CRP & $0.58^{\mathrm{a}}$ & $0.49^{\mathrm{a}}$ & $0.36^{\mathrm{a}}$ & $0.34^{\mathrm{a}}$ & $0.32^{\mathrm{a}}$ & $0.32^{\mathrm{a}}$ & $0.32^{\mathrm{a}}$ & $0.22^{\mathrm{b}}$ & $0.29^{\mathrm{a}}$ & $0.20^{c}$ & & \\
\hline ESR & $0.64^{\mathrm{a}}$ & $0.37^{\mathrm{a}}$ & $0.29^{\mathrm{a}}$ & $0.34^{\mathrm{a}}$ & $0.33^{\mathrm{a}}$ & $0.32^{\mathrm{a}}$ & $0.32^{\mathrm{a}}$ & $0.18^{c}$ & $0.29^{b}$ & $0.27^{\mathrm{b}}$ & $0.75^{\mathrm{a}}$ & \\
\hline
\end{tabular}

Abbreviations: CDAI Clinical Disease Activity Index, CRP C-reactive protein, DAS28-ESR Disease Activity Score in 28 joints with erythrocyte sedimentation rate, ESR erythrocyte sedimentation rate, HAQ Health Assessment Questionnaire, JSN joint space narrowing, SDAl Simple Disease Activity Index, SHS Sharp/van der Heijde score, SJC28 28-joint swollen joint count, TJC28 28-joint tender joint count

${ }^{\mathrm{a}} \mathrm{p}<0.0001$

${ }^{b} p<0.01$

${ }^{c} p<0.05$

${ }^{\mathrm{d}} p<0.001$

was an independent predictor of DAS28-ESR remission in TCZ-treated patients $(\mathrm{LR}=10.24, p=0.0014)$.

Because $14-3-3 \eta$ and CRP levels were significantly lower at 1 year in DAS28-ESR remitters treated with TCZ, Fisher's exact test was performed to assess the association of both of these markers with DAS28-ESRand CDAI-defined remission. In both instances, positivity of $14-3-3 \eta$ at 1 year, based on the cutpoint of $0.19 \mathrm{ng} / \mathrm{ml}$, was associated with clinical remission (DAS28-ESRdefined remission $\mathrm{LR}=6.96, p=0.01$; CDAI-defined remission $\mathrm{LR}=7.14, p=0.01$ ), whereas CRP positivity defined as $\geq 10 \mathrm{mg} / \mathrm{L}$ was not.

\section{Discussion}

In this cohort of Japanese patients with established RA, the results corroborate previously published findings

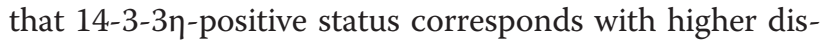
ease severity. We report, for the first time to our knowledge, that a positive status and higher levels of 14-3-3n based on different positivity cutpoints inform "moderate" and/or "high disease" activity states based on DAS28-ESR,
CDAI, and SDAI scores. We also corroborate previously

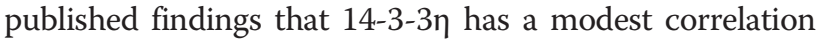
with the acute-phase reactants CRP and ESR [10,17] and illustrate for the first time that the addition of 14-3-3 $\eta$ to CRP is significantly useful in identifying patients in a CDAI-defined high disease state. In this regard, the LR for moderate to high disease categorization based on CDAI increased from 20.5 to 37.6 when $14-3-3 \eta$ was added to CRP. Although in this study we specifically evaluated $14-3-3 \eta$ in $R A$, in other diseases it has been reported that elevated expression of other 14-3-3 isoforms is associated with more severe disease or worse outcomes, including but not limited to cancer and CreutzfeldtJakob disease [18-26].

Although higher expression of 14-3-3 proteins has been noted to be associated with less favorable outcomes across different pathologies, whether these proteins are causal or exist as a consequence of disease is yet to be fully elucidated. Of interest, Maksymowych and colleagues reported, on the basis of their in vitro and ex vivo experiments, that extracellular $14-3-3 \eta$, in a

Table 3 Pretreatment 14-3-3n positivity and association with disease state

\begin{tabular}{|c|c|c|c|c|c|c|c|c|c|c|}
\hline \multirow{2}{*}{ Cutpoint } & & \multicolumn{3}{|c|}{ DAS28-ESR category ${ }^{a}$} & \multicolumn{3}{|l|}{ SDAI category } & \multicolumn{3}{|c|}{ CDAl category } \\
\hline & & $\geq 0.19 \mathrm{ng} / \mathrm{ml}$ & $\geq 0.40 \mathrm{ng} / \mathrm{ml}$ & $\geq 0.80 \mathrm{ng} / \mathrm{ml}$ & $\geq 0.19 \mathrm{ng} / \mathrm{ml}$ & $\geq 0.40 \mathrm{ng} / \mathrm{ml}$ & $\geq 0.80 \mathrm{ng} / \mathrm{ml}$ & $\geq 0.19 \mathrm{ng} / \mathrm{ml}$ & $\geq 0.40 \mathrm{ng} / \mathrm{ml}$ & $\geq 0.80 \mathrm{ng} / \mathrm{ml}$ \\
\hline \multirow[t]{2}{*}{ Pretreatment } & LR & 10.6 & 16.3 & 25.2 & 3.7 & 9.7 & 16.3 & 6.2 & 8.8 & 14.0 \\
\hline & $p$-value & 0.0011 & $<0.0001$ & $<0.0001$ & 0.16 (ns) & 0.0077 & 0.0003 & 0.045 & 0.012 & 0.0009 \\
\hline \multirow[t]{2}{*}{$1 \mathrm{yr}$} & LR & 10.1 & 5.1 & 2.6 & 2.2 & 1 & 1 & 2.2 & 1.1 & 0.8 \\
\hline & $p$-value & 0.0064 & 0.079 (ns) & 0.27 (ns) & 0.34 (ns) & 0.61 (ns) & 0.61 (ns) & 0.34 (ns) & 0.57 (ns) & 0.69 (ns) \\
\hline
\end{tabular}

Abbreviations: DAS28-ESR Disease Activity Score in 28 joints with erythrocyte sedimentation rate, SDAl Simple Disease Activity Index, CDAI Clinical Disease Activity Index, $L R$ likelihood ratio, $n s$ not significant

${ }^{\mathrm{a} C a l c u l a t e d}$ based on 145 patients for pretreatment and 146 for $1 \mathrm{yr}$ 


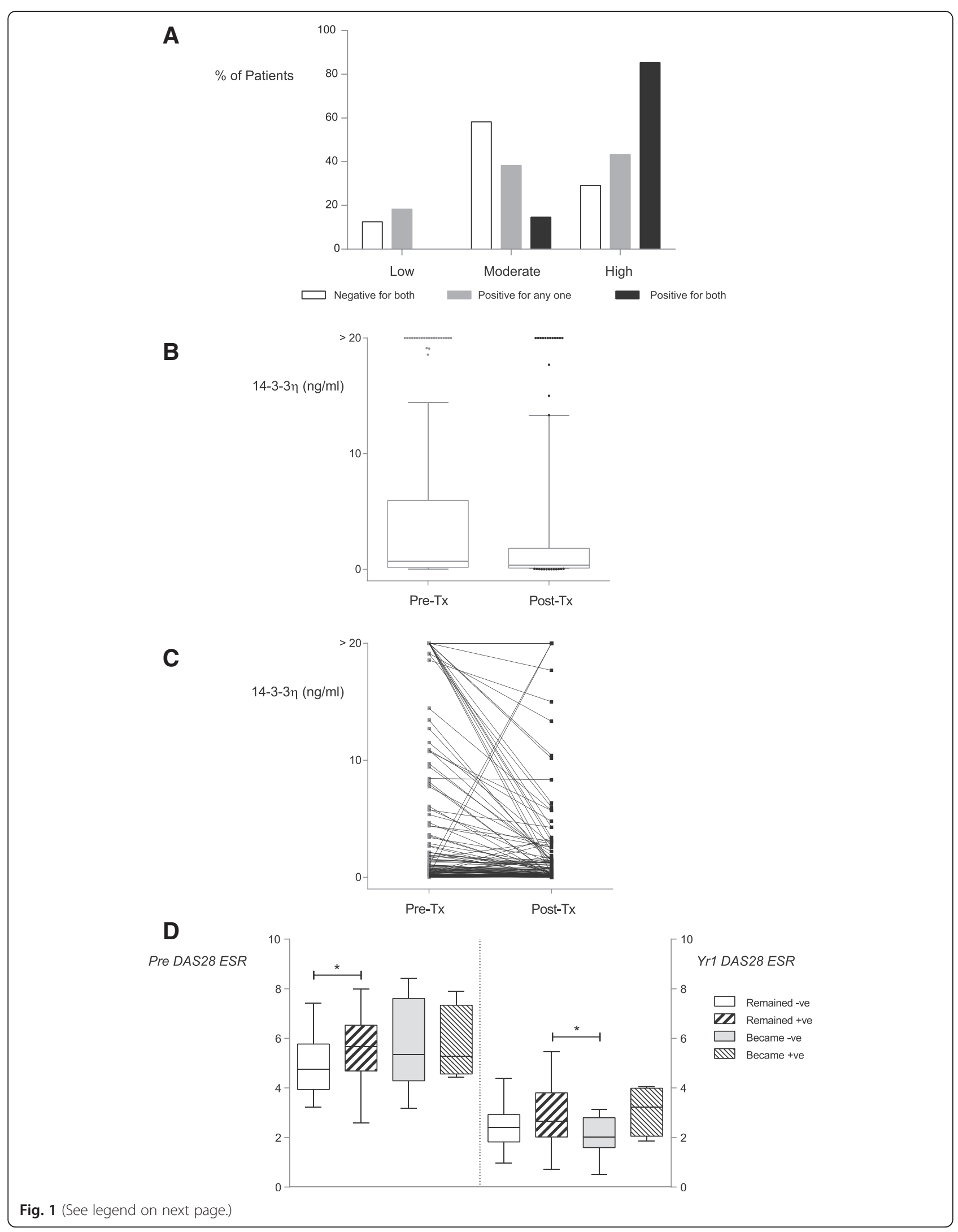


(See figure on previous page.)

Fig. 1 14-3-3n expression. a Clinical Disease Activity Index (CDAI)-defined disease states. The bar chart illustrates the relationship between 14-3-3n and/or C-reactive protein positivity and CDAl-defined disease status, $\mathbf{b}$ Changes between pre- and posttreatment. The box plot shows the change median levels of 14-3-3n over time, c Pairing by patient. The graph illustrates individual patients' changes between pretreatment and posttreatment 14-3-3n serum levels. $\mathbf{d}$ Disease Activity Score in 28 joints with erythrocyte sedimentation rate (DAS28-ESR) based on changes in 14-3-3n expression. The box plot illustrates changes in median DAS28-ESR expression as 14-3-3n positivity changes over time. *Significance values were calculated using Dunn's posttest

concentration-dependent manner using clinically relevant levels detectable in the serum of patients with RA, is capable of inducing both proinflammatory cytokines and chemokines and those factors that are directly involved in the degradation of cartilage and bone [17, 27]. More recently, they also reported that targeting 14-3-3n using an antibody-based approach in the collageninduced arthritis mouse model delayed the onset of disease and reduced the overall disease severity [28].

In the present study, $14-3-3 \eta$ levels at 1 year were also determined to be significantly lower across the whole cohort, as well as within each treatment group, when compared with the corresponding level before the initiation of treatment. Serial changes in 14-3-3 $\eta$ reflect the dynamic state of this marker wherein its modifiability over time, as well as its association with therapy response, is in clear contrast to RA biomarkers such as RF and/or ACPA, which are relatively undynamic with regard to treatment response [29]. We also report that reversion to a normal $14-3-3 \eta$ state (i.e., $\leq 0.19 \mathrm{ng} / \mathrm{ml}$ ) was associated with better clinical outcomes. In particular,

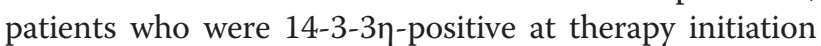
and reverted to a negative status at the 1-year follow-up had significantly lower DAS28-ESR scores than RP or BP patients. This association with disease activity is further corroborated by the fact that $88 \%$ of $14-3-3 \eta$ negative patients at 1 year were in remission or in a low disease activity state compared with $66 \%$ of $14-3-3 \eta$ positive patients. On the basis of these data, 14-3-3 $\eta$ may have utility as a marker of clinical response, and the

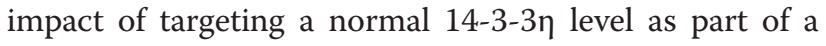
patient management strategy needs to be evaluated prospectively.

Because the ultimate goal for RA patient management is to achieve full clinical remission and halt radiographic damage and/or progression, more precise patient management through the use of markers such as 14-3-3 $\eta$ may assist in implementing treat-to-target strategies. Smolen et al. put forth a set of recommendations in which they stated that, with long-standing disease, as was the case for most patients in the present study, achieving low disease activity in those who are refractory to therapy is an important step in disease management, whereas in early disease, low disease activity should be considered a step toward clinical remission [30]. In the present study, we demonstrate that $14-3-3 \eta$ levels at 1 year, across the whole cohort, were significantly lower in those who achieved a EULAR-defined good response. When evaluated in relation to the type of therapy administered, lower 14-3-3ๆ pretreatment level was determined to be an independent predictor of DAS28-defined remission in patients who were treated with TCZ but not with any of the other classes of therapy. Moreover, 1-year 14-3-3n levels were associated with DAS28-ESRand CDAI-defined remission. It is noteworthy that CRP levels at therapy initiation were not an independent predictor of DAS28-ESR-defined remission, nor were the levels at 1 year informative of DAS28-ESR- or CDAIdefined remission. On the basis of these findings, further studies in larger cohorts are warranted to examine the utility of $14-3-3 \eta$ in predicting and monitoring response outcomes across different classes of therapy, more specifically in patients with early RA.

As this was an observational study, it has several limitations. First, the pretreatment characteristics of the MTX group were quite different from the other groups, with the patients being recruited in a consecutive manner. Second, the majority of patients in the ADA group and the TCZ group, as well as all patients in the TOF group, had histories of inadequate response to MTX.

Table 4 14-3-3n levels by therapy group at baseline and after 1 year of therapy

\begin{tabular}{lllll}
\hline Group & Sample size & Pretreatment 14-3-3n & $14-3-3 \eta$ at $1 \mathrm{yr}$ & $p$ Value \\
\hline Whole cohort & 149 & $0.70(0.17-5.96)$ & $0.37(0.11-1.82)$ & $<0.0001$ \\
Adalimumab & 49 & $0.62(0.16-4.66)$ & $0.38(0.13-1.40)$ & $<0.0001$ \\
Methotrexate & 23 & $0.67(0.17-1.89)$ & $0.33(0.11-1.44)$ & 0.0101 \\
Tocilizumab & 50 & $0.43(0.15-8.40)$ & $0.27(0.10-2.58)$ & 0.0007 \\
Tofacitinib & 27 & $1.30(0.21-9.46)$ & $1.26(0.11-3.07)$ & 0.013 \\
\hline
\end{tabular}

Median (interquartile range) 14-3-3n serum titers at baseline and at $1 \mathrm{yr}$ are compared with the whole cohort and each therapy group. Corresponding Wilcoxon matched-pairs signed-rank test values were calculated 
Table 5 Clinical response after 1 year, by therapy

\begin{tabular}{|c|c|c|c|c|c|c|c|c|c|c|}
\hline & All therapies & & ADA & & MTX & & TCZ & & TOF & \\
\hline Patients (n) & 149 & & 49 & & 23 & & 50 & & 27 & \\
\hline Pretreatment DAS28-ESR & $5.35(4.40-6.45)$ & & $5.33(4.34-627)$ & & $4.23(3.84-5.12)$ & & $5.43(4.57-6.51)$ & & $6.34(5.74-7.11)$ & \\
\hline DAS28-defined remission & Y & $N$ & Y & $N$ & Y & N & Y & $\mathrm{N}$ & Y & $N$ \\
\hline Patients (n) & 82 & 67 & 26 & 23 & 15 & 8 & 30 & 20 & 11 & 16 \\
\hline Pretreatment DAS28-ESR & $5.00(4.09-6.13)^{a}$ & $5.85(4.90-6.77)$ & $5.30(4.06-5.83)$ & $5.67(4.82-6.77)$ & $4.11(3.75-4.43)$ & $4.78(4.24-5.27)$ & $4.80(4.23-6.27)^{b}$ & $6.02(5.30-7.44)$ & $6.60(5.60-7.11)$ & $6.28(5.78-7.09)$ \\
\hline Response rate & $55 \%$ & & $53 \%$ & & $65 \%$ & & $60 \%$ & & $41 \%$ & \\
\hline Pretreatment 14-3-3n (ng/ml) & $0.50(0.16-4.95)$ & $1.05(0.19-7.75)$ & $1.16(0.20-9.06)$ & $0.47(0.13-2.14)$ & $0.70(0.17-1.89)$ & $0.42(0.16-14.55)$ & $0.23(0.09-3.03)^{b}$ & $4.02(0.46-19.77)$ & $1.05(0.30-9.46)$ & $1.56(0.20-11.58)$ \\
\hline 1-yr 14-3-3n (ng/ml) & $0.33(0.10-1.45)$ & $0.62(0.14-3.11)$ & $0.75(0.14-2.96)$ & $0.30(0.13-1.17)$ & $0.37(0.11-0.62)$ & $0.28(0.07-18.33)$ & $0.13(0.08-0.75)^{b}$ & $1.52(0.28-5.57)$ & $1.24(0.11-1.85)$ & $1.27(0.11-5.08)$ \\
\hline Pretreatment CRP (mg/ml) & $0.73(0.15-3.12)$ & $1.14(0.26-3.40)$ & $0.62(0.14-5.01)$ & $1.14(0.40-5.32)$ & $0.36(0.06-0.83)$ & $0.18(0.08-1.34)$ & $0.92(0.14-2.18)$ & $2.67(0.40-3.50)$ & $2.97(0.56-5.22)$ & $1.04(0.33-2.98)$ \\
\hline 1-yr CRP (mg/ml) & $0.03(0.01-0.09)^{b}$ & $0.09(0.02-0.37)$ & $0.04(0.02-0.13)^{a}$ & $0.14(0.07-1.22)$ & $0.05(0.02-0.13)$ & $0.12(0.03-0.31)$ & $0.01(0.00-0.030)^{c}$ & $0.03(0.01-0.18)$ & $0.03(0.02-0.16)$ & $0.04(0.03-0.28)$ \\
\hline EULAR-defined good response & Y & N & Y & N & Y & N & Y & $\mathrm{N}$ & Y & N \\
\hline Patients (n) & 101 & 43 & 30 & 19 & 16 & 4 & 40 & 8 & 15 & 12 \\
\hline Pretreatment DAS28-ESR & $5.32(4.33-6.45)$ & $5.77(4.70-6.55)$ & $5.33(4.33-6.03)$ & $5.32(4.32-6.77)$ & $4.21(3.83-5.03)$ & $4.42(3.32-5.37)$ & $5.02(4.37-6.61)$ & $5.75(4.83-6.02)$ & $6.60(5.74-7.25)$ & $6.10(5.53-6.60)$ \\
\hline Response rate & $70 \%$ & & $61 \%$ & & $80 \%$ & & $83 \%$ & & $56 \%$ & \\
\hline Pretreatment 14-3-3n (ng/ml) & $0.62(0.16-5.02)$ & $1.48(0.20-12.72)$ & $0.61(0.12-3.61)$ & $0.70(0.24-5.84)$ & $0.65(0.12-1.03)$ & $1.05(0.20-14.82)$ & $0.37(0.16-7.33)$ & $10.34(0.19->20)$ & $1.05(0.30-8.16)$ & $1.56(0.20-14.02)$ \\
\hline 1-yr 14-3-3n (ng/ml) & $0.28(0.10-1.51)^{b}$ & $0.80(0.27-5.99)$ & $0.45(0.11-1.45)$ & $0.36(0.22-1.41)$ & $0.30(0.10-0.47)^{c}$ & $7.39(0.53->18.33)$ & $0.18(0.08-2.02)^{b}$ & $3.42(0.39->20)$ & $1.24(0.11-1.85)$ & 1.35 (0.19-9.06) \\
\hline Pretreatment CRP (mg/ml) & $0.96(0.21-3.35)$ & $0.64(0.23-3.08)$ & $0.80(0.27-5.33)$ & $0.68(0.30-4.20)$ & $0.16(0.05-0.80)$ & $0.33(0.10-1.34)$ & $1.10(0.20-3.11)$ & $0.60(0.16-2.99)$ & $2.18(0.77-4.28)$ & $1.04(0.26-3.58)$ \\
\hline 1-yr CRP (mg/ml) & $0.03(0.01-0.12)^{c}$ & $0.11(0.03-0.50)$ & $0.05(0.02-0.14)^{a}$ & $0.13(0.07-1.50)$ & $0.04(0.02-0.24)$ & $0.13(0.03-0.22)$ & $0.01(0.00-0.05)^{a}$ & $0.06(0.02-1.36)$ & $0.03(0.02-0.16)$ & $0.07(0.02-0.28)$ \\
\hline
\end{tabular}


Thus, this reflects the shorter symptom duration and lower pretreatment DAS28-ESR in the MTX group. Last, it would have been ideal if the sample sizes and response rates across the different treatment groups had been balanced.

\section{Conclusions}

Positivity of $14-3-3 \eta$ is associated with more severe disease and combines with CRP to identify patients at higher risk. Serial decreases in 14-3-3 $\eta$ levels in response to therapy are associated with better clinical outcomes, whereas increases or sustained levels of the marker are associated with a worse prognosis. Pretreatment 14-3-3n level was an independent predictor of DAS28-ESRdefined remission in patients treated with TCZ.

\begin{abstract}
Abbreviations
ACPA: anticitrullinated protein antibodies; ADA: adalimumab; BN: became negative; BP: became positive; CDAl: Clinical Disease Activity Index; CRP: C-reactive protein; DAS28: Disease Activity Score in 28 joints; ELISA: enzyme-linked immunosorbent assay; ESR: erythrocyte sedimentation rate; EULAR: European League Against Rheumatism; HAQ: Health Assessment Questionnaire; IQR: interquartile range; JSN: joint space narrowing; LR: likelihood ratio; MTX: methotrexate; RA: rheumatoid arthritis; RF: rheumatoid factor; RP: remained positive; SD: standard deviation; SDAI: Simple Disease Activity Index; SDMARD: synthetic disease-modifying antirheumatic drug; SHS: Sharp/van der Heijde score; SJC28: 28-joint swollen joint count; SP: stayed positive; TCZ: tocilizumab; TJC28: 28-joint tender joint count; TOF: tofacitinib.

\section{Competing interests}

$\mathrm{SH}$ has received consulting and speaking fees from AbbVie, Eisai, Bristol-Myers Squibb, Chugai Pharmaceutical Co., Janssen Pharmaceuticals, Takeda Pharmaceutical Co., Pfizer, and Astellas Pharma. AM is an employee of Augurex Life Sciences Corporation. YG is an employee of Augurex Life Sciences Corporation. $\mathrm{KH}$ has no competing interests to declare. YT has received consulting fees, speaking fees, and/or honoraria from AbbVie, Daiichi-Sankyo, Chugai Pharmaceutical Co., Takeda Pharmaceutical Co., Mitsubishi Tanabe Pharma, Bristol-Myers Squibb, Astellas Pharma, Eisai, Janssen Pharmaceuticals, Pfizer, Asahi Kasei, Eli Lilly and Company, GlaxoSmithKline, UCB, Teijin, MSD Pharmaceuticals, and Santen Pharmaceutical Co., and has received research grants from Mitsubishi Tanabe Pharma, Takeda Pharmaceutical Co., Chugai Pharmaceutical Co., Astellas Pharma, Eisai, Taisho Toyama Pharmaceutical Co., Kyowa Hakko Kirin, AbbVie, and Bristol-Myers Squibb. All authors declare that they have no nonfinancial competing interests.
\end{abstract}

\section{Authors' contributions}

SH provided clinical samples, analyzed data, and drafted the manuscript. AM analyzed data and drafted the manuscript. YG tested $14-3-3 \eta$ and reviewed the manuscript. $\mathrm{KH}$ analyzed data and reviewed the manuscript. YT provided clinical samples, analyzed data, and drafted the manuscript. All authors read and approved the final manuscript.

\section{Acknowledgements}

We thank Drs. Davison, Murphy, and Savill for their assistance with data analysis and manuscript writing. Grants and financial support were received from Augurex Life Sciences Corporation, Vancouver, BC, Canada.

\section{Author details}

${ }^{1}$ First Department of Internal Medicine, School of Medicine, University of Occupational and Environmental Health, 1-1 Iseigaoka, Yahatanishi, Kitakyushu 807-8555, Japan. ${ }^{2}$ Augurex Life Sciences Corporation, Vancouver, BC, Canada.

Received: 21 May 2015 Accepted: 25 September 2015

Published online: 09 October 2015

\section{References}

1. Aletaha D, Neogi T, Silman AJ, Funovits J, Felson DT, Bingham III CO, et al. 2010 rheumatoid arthritis classification criteria: an American College of Rheumatology/European League Against Rheumatism collaborative initiative. Arthritis Rheum. 2010;62:2569-81.

2. Coulthard LR, Geiler J, Mathews RJ, Church LD, Dickie LJ, Cooper DL, et al. Differential effects of infliximab on absolute circulating blood leucocyte counts of innate immune cells in early and late rheumatoid arthritis patients. Clin Exp Immunol. 2012;170:36-46.

3. Raza K, Falciani F, Curnow SJ, Ross EJ, Lee CY, Akbar AN, et al. Early rheumatoid arthritis is characterized by a distinct and transient synovial fluid cytokine profile of T cell and stromal cell origin. Arthritis Res Ther. 2005;7:R784-95.

4. Smolen JS, Van Der Heijde DM, St Clair EW, Emery P, Bathon JM, Keystone E, et al. Predictors of joint damage in patients with early rheumatoid arthritis treated with high-dose methotrexate with or without concomitant infliximab: results from the ASPIRE trial. Arthritis Rheum. 2006;54:702-10.

5. Emery P, Genovese MC, van Vollenhoven R, Sharp JT, Patra K, Sasso EH. Less radiographic progression with adalimumab plus methotrexate versus methotrexate monotherapy across the spectrum of clinical response in early rheumatoid arthritis. J Rheumatol. 2009;36:1429-41. A published erratum appears in. J Rheumatol. 2010;37:1081.

6. Smolen JS, Han C, Bala M, Maini RN, Kalden JR, van der Heijde D, et al. Evidence of radiographic benefit of treatment with infliximab plus methotrexate in rheumatoid arthritis patients who had no clinical improvement: a detailed subanalysis of data from the Anti-Tumor Necrosis Factor Trial in Rheumatoid Arthritis with Concomitant Therapy study. Arthritis Rheum. 2005;52:1020-30.

7. Landewé R, van der Heijde D, Klareskog L, van Vollenhoven R, Fatenejad S. Disconnect between inflammation and joint destruction after treatment with etanercept plus methotrexate: results from the trial of etanercept and methotrexate with radiographic and patient outcomes. Arthritis Rheum. 2006:54:3119-25

8. Aletaha D, Alasti F, Smolen JS. Rituximab dissociates the tight link between disease activity and joint damage in rheumatoid arthritis patients. Ann Rheum Dis. 2013;72:7-12.

9. Kilani RT, Maksymowych WP, Aitken A, Boire G, St-Pierre Y, Li Y, et al. Detection of high levels of 2 specific isoforms of 14-3-3 proteins in synovial fluid from patients with joint inflammation. J Rheumatol. 2007;34:1650-7.

10. Maksymowych WP, Naides SJ, Bykerk V, Siminovitch KA, van Schaardenburg D, Boers $M$, et al. Serum $14-3-3 \eta$ is a novel marker that complements current serological measurements to enhance detection of patients with rheumatoid arthritis. J Rheumatol. 2014;41:2104-13.

11. Marotta A, Cherkas Y, Dasgupta B, Lamberth S, Hayden K, Brodmerkel C, et al. Serum 14-3-3n is an RA specific mechanistic marker [abstract B030]. Inflamm Res. 2015;64 Suppl 2:S114.

12. Naides SJ, Zhukov OS, Rivera JG, Abolhosn RW, Rowland CM, Popov JM, et al. Serum 14-3-3n protein differentiates osteoarthritis from inflammatory arthritis [poster 0168]. Ann Rheum Dis. 2015;74 Suppl 2:255. doi:10.1136/annrheumdis2015-eular.6498.

13. Hughes N, Boss S, Longe R, Sohal R, Jimenez C, Gui Y, et al. Independent validation of the 14-3-3n assay: a diagnostic RA marker [abstract 111]. Presented at the 2015 Canadian Rheumatology Association (CRA) Annual Meeting, Quebec, QC, Canada, 5 February 2015.

14. Naides SJ, Zhukov OS, Abolhosn RW, Popov JM. Chaperonin protein 14-3-3n $(\eta)$ in rheumatoid arthritis and arthritogenic viral infections [abstract 1390]. Arthritis Rheum. 2013;65 Suppl 10:S587-8. doi:10.1002/art.2013.65.issue-s10.

15. Arnett FC, Edworthy SM, Bloch DA, McShane DJ, Fries JF, Cooper NS, et al. The American Rheumatism Association 1987 revised criteria for the classification of rheumatoid arthritis. Arthritis Rheum. 1988;31:315-24.

16. van Gestel AM, Prevoo ML, van 't Hof MA, van Rijswijk MH, van de Putte LB, van Riel PL. Development and validation of the European League Against Rheumatism response criteria for rheumatoid arthritis. Comparison with the preliminary American College of Rheumatology and the World Health Organization/International League Against Rheumatism Criteria. Arthritis Rheum. 1996:39:34-40.

17. Maksymowych WP, van der Heijde D, Allaart CF, Landewé R, Boire G, Tak PP, et al. $14-3-3 \eta$ is a novel mediator associated with the pathogenesis of rheumatoid arthritis and joint damage. Arthritis Res Ther. 2014;16:R99.

18. Wu Q, Liu CZ, Tao LY, Yu L, Liu W, Chen SS, et al. The clinicopathological and prognostic impact of 14-3-3 protein isoforms expression in human 
cholangiocarcinoma by immunohistochemistry. Asian Pac J Cancer Prev. 2012;13:1253-9.

19. Nakamura Y, Oshima K, Naoi Y, Nakayama T, Kim SJ, Shimazu K, et al. 14-3$3 \sigma$ expression is associated with poor pathological complete response to neoadjuvant chemotherapy in human breast cancers. Breast Cancer Res Treat. 2012;134:229-36.

20. Zhou WH, Tang F, Xu J, Wu X, Feng ZY, Li HG, et al. Aberrant upregulation of 14-3-3o expression serves as an inferior prognostic biomarker for gastric cancer. BMC Cancer. 2011;11:397.

21. Ko BS, Chang TC, Hsu C, Chen YC, Shen TL, Chen SC, et al. Overexpression of $14-3-3 \varepsilon$ predicts tumour metastasis and poor survival in hepatocellular carcinoma. Histopathology. 2011;58:705-11.

22. Boesenberg-Grosse C, Schulz-Schaeffer WJ, Bodemer M, Ciesielczyk B, Meissner B, Krasnianski A, et al. Brain-derived proteins in the CSF: do they correlate with brain pathology in CJD? BMC Neurol. 2006;6:35.

23. Jayaratnam S, Khoo AK, Basic D. Rapidly progressive Alzheimer's disease and elevated 14-3-3 proteins in cerebrospinal fluid. Age Ageing. 2008:37:467-9.

24. Colucci M, Roccatagliata L, Capello E, Narciso E, Latronico N, Tabaton M, et al. The 14-3-3 protein in multiple sclerosis: a marker of disease severity. Mult Scler. 2004;10:477-81.

25. Umahara T, Uchihara T, Tsuchiya K, Nakamura A, Iwamoto T. Intranuclear localization and isoform-dependent translocation of 14-3-3 proteins in human brain with infarction. J Neurol Sci. 2007;260:159-66.

26. Miller RF, Green AJ, Giovannoni G, Thompson EJ. Detection of 14-3-3 brain protein in cerebrospinal fluid of HIV infected patients. Sex Transm Infect. 2000;76:408.

27. O'Mahony A, Berg EL, Maksymowych WP, Gui Y, Marotta A. Profiling of 143-3n in human primary cell based BioMAP disease models reveals a unique pro-inflammatory phenotypic signature consistent with RA-inflammation biology [abstract 1975]. Arthritis Rheum. 2014;63 Suppl 10:S868.

28. Abulrob A, Mercier M, Corluka S, Mackenzie R, Raphael S, Michienzi S, et al. 14-3-3n as a novel RA drug target: anti-14-3-3n monoclonal antibody delays the onset and mitigates the severity of arthritis in CIA mice [poster 0073]. Ann Rheum Dis. 2015;74 Suppl 2:218.

29. Barra L, Bykerk V, Pope JE, Haraoui BP, Hitchon CA, Thorne JC, et al. Anticitrullinated protein antibodies and rheumatoid factor fluctuate in early inflammatory arthritis and do not predict clinical outcomes. J Rheumatol. 2013;40:1259-67.

30. Smolen JS, Aletaha D, Bijlsma JWJ, Breedveld FC, Boumpas D, Burmester G, et al. Treating rheumatoid arthritis to target: recommendations of an international task force. Ann Rheum Dis. 2010;69:631-7. A published erratum appears in Ann Rheum Dis. 2011;70:1519.

\section{Submit your next manuscript to BioMed Central and take full advantage of:}

- Convenient online submission

- Thorough peer review

- No space constraints or color figure charges

- Immediate publication on acceptance

- Inclusion in PubMed, CAS, Scopus and Google Scholar

- Research which is freely available for redistribution 